\title{
Direct-Acting Oral Anticoagulants (DOACs) in Cirrhosis and Cirrhosis-Associated Portal Vein Thrombosis
}

\author{
Ethan M. Weinberg, MD ${ }^{1, *}$ Julia Palecki, BA ${ }^{1, *}$ K. Rajender Reddy, MD ${ }^{1}$ \\ ${ }^{1}$ Division of Gastroenterology and Hepatology, Perelman School of \\ Medicine, University of Pennsylvania, Philadelphia, Pennsylvania \\ Address for correspondence K. Rajender Reddy, MD, Ruimy Family \\ President's Distinguished Professor of Medicine, Division of \\ Hepatology, Perelman School of Medicine, University of Pennsylvania, \\ Semin Liver Dis 2019;39:195-208. \\ 2, Dulles, 3400 Spruce Street, Philadelphia, PA 19104 \\ (e-mail: Rajender.reddy@uphs.upenn.edu).
}

\begin{abstract}
Keywords

- portal vein thrombosis

- cirrhosis

- anticoagulation

- DOAC

- NOAC

Direct-acting oral anticoagulants (DOACs) have provided benefit in patients requiring anticoagulation for certain diseases by decreasing the burden of subcutaneous injections and the requirement for frequent monitoring through regular blood tests, to ensure adequacy of the therapeutic doses. Studies have demonstrated DOACs to be as safe, and in some instance safer, compared with traditional anticoagulants in the general population. However, the studies evaluating DOACs excluded patients with cirrhosis, a condition associated with an increased risk of developing portal vein thrombosis (PVT). Warfarin or low-molecular weight heparin are the standard-of-care treatment for acute PVT in cirrhosis, although there is enthusiasm in a paradigm shift switching to DOACs for the treatment of acute PVT in cirrhosis, particularly since the release of DOAC antidotes. This article reviews the current Food and Drug Administration-approved DOACs, hepatic metabolism of DOACs, pharmacokinetics of DOACs in patients with cirrhosis, safety of DOACs (including bleeding, hepatotoxicity, and pregnancy), current treatment guidelines for PVT in cirrhosis, and studies evaluating the use of DOACs in cirrhosis and for the treatment of PVT in cirrhosis. The potential use of DOACs for PVT primary prophylaxis in at-risk patients with cirrhosis and the possible antifibrotic effects of DOACs are also discussed.
\end{abstract}

There are two widespread fallacies pertaining to cirrhosis and anticoagulation: the first is that cirrhosis is a contraindication to anticoagulation due to an increased bleeding risk. The second is that those with an elevated international normalized ratio (INR) do not require anticoagulation because they are already "auto-anticoagulated." 1 Both of these common misconceptions among the medical community have recently been dispelled. ${ }^{1}$ Patients with cirrhosis are at similar risk as those without cirrhosis for clotting and other events, such as thromboembolic phenomenon in atrial fibrillation or venous thromboembolism (VTE) prevention during hospitalizations for acute illness, and as such receive anticoagulation

Co-First Authors. with no added risk. However, the leading reason for anticoagulation in patients with cirrhosis is portal vein thrombosis (PVT). PVT has historically been classified into four categories: cirrhotic or noncirrhotic, acute or chronic, occlusive or nonocclusive, and malignant or nonmalignant. A 2016 paper proposed a new nomenclature for PVT to allow for precision of language and to aid in future clinical studies. ${ }^{2}$ PVT is being increasingly recognized in patients with cirrhosis, with higher incidence in those with decompensated cirrhosis. ${ }^{3}$ The clinical manifestations of PVT depend on the extent of the obstruction and the rapidity of development. ${ }^{2,3}$ Often, recent PVT is asymptomatic. However, patients may present with abdominal pain, often accompanied by splenomegaly, fever, and/or ascites-these would be categorized as acute. ${ }^{2,3}$ Chronic PVT

Copyright $\odot 2019$ by Thieme Medical Publishers, Inc., 333 Seventh Avenue, New York, NY 10001, USA. Tel: +1(212) 584-4662.
DOI https://doi.org/ $10.1055 / \mathrm{s}-0039-1679934$. ISSN 0272-8087.
April 12, 2019 
may be asymptomatic and discovered incidentally when abdominal imaging is obtained for other reasons, or may present with complications of portal hypertension such as ascites, gastroesophageal variceal bleeding, or even manifest with portal cholangiopathy. ${ }^{3}$ Over the past decade, there has been an increased understanding of the pathophysiology of PVT. However, there is a relative dearth of studies examining PVT in patients with cirrhosis compared with studies examining other decompensation events, such as ascites and hepatic encephalopathy. Additionally, while primary prophylaxis is well accepted to prevent events such as spontaneous bacterial peritonitis and variceal hemorrhage, with antibiotics and $\beta$ blockers, respectively, primary prophylaxis with anticoagulants is less commonly used to prevent PVT in patients with cirrhosis, partially due to fear of bleeding complications., ${ }^{4,5}$ With the advent of new direct-acting oral anticoagulants (DOACs), the approach to the prevention and treatment of PVT is in transition. This review examines the approved uses, safety concerns, and potential role for DOACs in cirrhosis with a focus on their use for PVT. Additionally, a plausible additional role as an antifibrotic will be discussed.

\section{Risk for Thrombosis in Cirrhosis}

\section{Portal Vein Thrombosis}

The prevalence of PVT among those with cirrhosis has been estimated to be between 10 and $25 \%$, with an increase in incidence being strongly associated with the severity of liver disease. $^{6,7}$ Inherited prothrombotic disorders have been associated with an increased risk of developing PVT. ${ }^{8,9}$ For instance, the presence of the prothrombin (PT) gene mutation 20210 has been reported to increase the risk of PVT more than fivefold. ${ }^{4}$ Other thrombophilic gene mutations including antithrombin, protein $\mathrm{C}$, and protein $\mathrm{S}$ deficiencies have also been implicated. ${ }^{9}$ Reduced portal flow velocity of less than $15 \mathrm{~cm} / \mathrm{s}$ in patients with cirrhosis appears to have a significant predictive variable for the development of PVT (91.7 vs. $19.7 \%){ }^{10}$ Few studies have defined the natural course of acute and untreated nonmalignant PVT in those with cirrhosis and without interventions. A prospective cohort study of partial nonmalignant PVT without anticoagulant therapy found that, after a mean follow-up time of 20 months, PVT worsened in close to $30 \%$ of cases and correlated with increased rates of hepatic decompensations and death. ${ }^{11}$ Another prospective study on those with untreated nonmalignant PVT noted that, after a mean follow-up time of 27 months, the partial PVT progressed in almost $50 \%$ of patients and this correlated with the severity of cirrhosis. ${ }^{12}$ It is not clear if progression of a partially occluding PVT to completely occluding PVT leads to further hepatic decompensation or whether worsening liver disease is the nidus for a PVT to transition from partial to complete occlusion. $^{12}$

The most recent American Association for the Study of Liver Diseases (AASLD) guidelines for the management of PVT in cirrhosis were published in 2009; at that time, the AASLD committee did not provide specific anticoagulation guidance for PVT, but recommended clinical decisions be made on a case-by-case basis depending on the presence of prothrombotic conditions, symptoms, or extension into the superior mesenteric vein (SMV). ${ }^{13}$ The European Association for the Study of the Liver (EASL) guidelines on vascular disorders of the liver, published in 2016, recommends evaluating for the presence of at-risk varices and initiating therapy (either band ligation or nonselective $\beta$ blocker) prior to initiation of anticoagulation treatment for PVT in cirrhosis. ${ }^{14}$ Similar to AASLD, EASL does not make broad recommendations on the choice of therapy for PVT, but that each institution/liver unit, should follow their own treatment algorithm until randomized trials have demonstrated a preferred drug. ${ }^{14}$ The risk and benefits of treatment with anticoagulation for PVT in cirrhosis have been debated for years. The purported benefits of anticoagulation can be divided into surrogate outcomes (recanalization of the portal vein and progression of PVT) and clinical outcomes (variceal bleeding, liver transplantation, and death) compared with the risks (bleeding associated due to anticoagulation). ${ }^{15}$ Loffredo et al compiled a meta-analysis evaluating the effects of traditional anticoagulation (no DOACs studies included) for PVT in cirrhosis, and reported that anticoagulation increased PV recanalization and decreased the incidence of PVT progression and variceal bleeding (though variceal bleeding improvements were limited to low-molecularweight heparin [LMWH]). ${ }^{15}$ Additionally, it appears that the bleeding risk associated with anticoagulation treatment for PVT in cirrhosis is not statistically greater than no treatment at all. ${ }^{15}$ Studies large enough to evaluate the impact of anticoagulation treatment of PVT in cirrhosis in delaying liver transplantation and death have not yet been performed. However, the indirect benefits of anticoagulation for PVT in cirrhosis in liver transplant candidates can be inferred, as PVT at the time of liver transplant can increase surgical complications, including longer operative time and more intraoperative blood loss, and postoperative complications, including bleeding complications and recurrent PVT. ${ }^{16-19}$

\section{Non-PVT Venous Thromboembolism}

A large U.S. inpatient database (the National Inpatient Sample) analysis noted that hospitalized patients with cirrhosis under 45 years old were more likely to experience non-PVT VTE than patients without cirrhosis. ${ }^{20}$ Hospitalized patients with cirrhosis that were diagnosed with a VTE had an average length of stay of more than double that of patients with cirrhosis and without a VTE. ${ }^{20}$ The presence of VTE increased in-hospital mortality rates among patients with and without cirrhosis. ${ }^{20} \mathrm{~A}$ different study employing the National Inpatient Sample (2005) found that patients with cirrhosis that were diagnosed with a VTE were, on average, more malnourished, but less likely to have complications of liver disease during that admission (variceal bleeding, ascites, or coagulopathy). ${ }^{21}$ In contrast, another large database study using discharge codes for chronic alcoholic and nonalcoholic liver disease found that patients with these diagnosis codes had low rates of VTE; however, these groupings included a large number of patients without cirrhosis. ${ }^{22}$ 
Several small single-center reports have attempted to tease out the risk factors for VTE among patients with cirrhosis. Using a retrospective case-control approach, Northup et al were the first to evaluate the clinical characteristics of non-PVT VTE in hospitalized patients with cirrhosis, finding no difference in the INR between patients with cirrhosis that are diagnosed with a VTE and the controls; the VTE cases had lower serum albumin than the controls. $^{23}$ Four additional case-control studies reported that patients with chronic liver disease that experience VTE had lower serum albumin, although this has not been corroborated in prospective studies. ${ }^{24-26}$ Another singlecenter retrospective study demonstrated an increase in incidence of VTE in hospitalized patients with cirrhosis based on Child-Turcotte-Pugh (CTP) class, but not based on INR. ${ }^{27}$ The authors noted that an astounding $75 \%$ of the patients did not receive any form of anticoagulation prophylaxis (mechanical/compression stockings or pharmacologic). ${ }^{27}$ While patients with cirrhosis that experience a VTE had a higher 30-day mortality risk than those without cirrhosis, the proportion of deaths attributable to pulmonary embolism (PE) appeared to be the same in each group. ${ }^{28}$ It is these studies that have helped debunk the "auto-anticoagulation" belief that is widely perceived in clinical care.

\section{Mechanism of Thrombosis and Role of DOACs as Antifibrotic Agents}

There is a growing body of literature that demonstrates the interconnection between liver disease progression and prothrombotic states within the liver and portal system. In cirrhosis, there is a rebalancing of both pro- and anticoagulant factors that increase the risk for both bleeding and thrombosis (-Fig. 1). ${ }^{1}$ While there is a decrease in PT production and, thus, less thrombin formation in cirrhosis, there is a simultaneous decrease in antithrombin production. ${ }^{29}$ Kremers et al noted that the PT-thrombin-antithrombin equilibrium is altered in the patient with cirrhosis such that thrombin is formed more quickly and inactivated more slowly than in a healthy control. ${ }^{29}$ The change in thrombin kinetics in cirrhosis is a necessary adaptation in the setting of diminished levels of PT and antithrombin; however, the prolongation of activated throm-

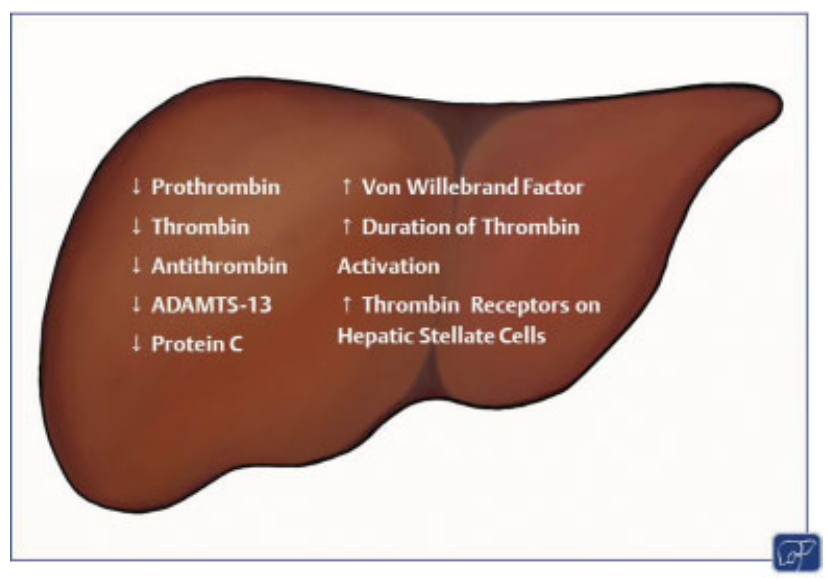

Fig. 1 Relative changes in thrombotic factors in cirrhosis. bin may be further promoting liver fibrosis. Hepatic stellate cells (HSCs), the drivers of fibrosis in liver disease, upregulate thrombin receptors in response to liver injury. ${ }^{30}$ The increased half-life of thrombin paired with an increase of its receptors on HSCs may perpetuate liver damage in cirrhosis. ${ }^{30,31}$ Indeed, in vivo studies using dabigatran and argatroban, both Food and Drug Administration (FDA)-approved thrombin inhibitors, demonstrate antifibrotic effects in the skin, lung, and liver. ${ }^{32-35}$ Studies from the Luyendek laboratory demonstrated in two separate mouse models of fatty liver disease that both argatroban and dabigatran decreased inflammation and subsequent fibrosis associated with steatohepatitis. ${ }^{33,34}$

Inhibiting targets further along in the coagulation cascade also appears to prevent further liver injury in in vivo models. The most studied of these targets is factor Xa. LMWHs (enoxaparin and dalteparin) have historically been the most commonly used factor Xa inhibitors in studies focusing on liver fibrosis given their ease of administration compared with heparin, its cost, and well-known safety profile compared with the newer DOACs. LMWH has been demonstrated to decrease liver fibrosis in chemically induced liver fibrosis and cirrhosis rat models. ${ }^{36,37}$ There are conflicting data on the effects of LMWH and DOACs on portal hypertension in cirrhosis rat models. ${ }^{38-40}$ One group has demonstrated that both enoxaparin and rivaroxaban decreased portal hypertension and fibrosis in the rat cirrhosis model. It was hypothesized that these effects are mediated through deactivation of HSCs, as desmin and $\alpha$-smooth muscle actin were both decreased in the rats treated with a factor Xa inhibitor. ${ }^{40}$ However, another study demonstrated no improvements in portal hypertension in cirrhotic rats treated with enoxaparin. ${ }^{39}$ Like thrombin, inhibition of factor Xa has also been linked to decreased fibrosis formation in the skin, but at the cost of decreased wound healing. ${ }^{41}$

While most factors in the coagulation cascade are reduced in end-stage liver disease, von Willebrand factor (VWF) is increased. ${ }^{1}$ Higher levels of VWF are correlated with portal hypertension, hepatic decompensations, and death. ${ }^{42}$ Increased VWF activity has been associated with poor clinical outcomes in patients with acute-on-chronic liver failure. ${ }^{43}$ Depletion of VWF in in vivo mice models of acute liver injury resulted in decreased liver fibrosis. ${ }^{44}$ In contrast, ADAMTS13 (a disintegrin and metalloproteinase with thrombospondin type 1 motif, member 13), a VWF cleaving enzyme, is often decreased in cirrhosis. A study evaluating the effects of ADAMTS13 in a mouse model of nonalcoholic fatty liver disease demonstrated that ADAMTS-13 deficiency led to increased fibrosis and microthromboses in the liver. ${ }^{45}$ An exploratory study evaluating coagulation factors in patients with PVT demonstrated a significant increase in VWF and decrease in ADAMTS-13 activity among those patients with PVT compared with matched controls of patients with cirrhosis. ${ }^{46}$ Based on many of the in vivo and human studies, it seems that therapeutic targeting of a component of the coagulation cascade could help to ameliorate end-stage liver disease while also preventing PVT.

Villa et al performed a randomized controlled trial to evaluate the safety and efficacy of enoxaparin in preventing 
PVT in patients with advanced cirrhosis, defined as ChildPugh class B7-C10. ${ }^{47}$ Patients treated with enoxaparin demonstrated significantly lower incidence of PVT at all time points evaluated (at 48 weeks $[0$ vs. $16.6 \%$, $p=0.025$ ], at 96 weeks [ 0 vs. $27.7 \%, p=0.001$ ], and at the end of the follow-up period [8.8 vs. $27.7 \%, p=0.048]) .{ }^{47}$ Most importantly, patients treated with enoxaparin demonstrated lower rates of liver decompensation (11.7 vs. $59.4 \%$, $p<0.0001)$ and lower mortality (8/34 vs. $13 / 36)$, suggesting that enoxaparin may delay hepatic decompensation and improve survival. ${ }^{47}$ There were three bleeding episodes from ruptured esophageal varices, two of which occurred in the treatment group, and three episodes of epistaxis, two of which occurred in the treatment group. ${ }^{47}$ Overall, this trial concluded that anticoagulant therapy was safe and effective in preventing PVT in patients with cirrhosis and also that such intervention improved survival. ${ }^{47}$

\section{Approved Uses for DOACs}

The pharmacology of traditional anticoagulants, DOACs, and their effects on the coagulation cascade has been written about extensively. ${ }^{48}$ Briefly, warfarin antagonizes vitamin $\mathrm{K}$, which is a necessary cofactor for factors II, VII, XI, and X, and requires frequent monitoring of levels. Heparin and LMWH function as indirect inhibitors of factor Xa. Rivaroxaban, apixaban, edoxaban, and betrixaban inhibit factor Xa directly. Dabigatran acts as a direct thrombin inhibitor (-Fig. 2).

There are currently five FDA-approved DOACS: dabigatran (Pradaxa, direct thrombin inhibitor), rivaroxaban (Xarelto, factor Xa inhibitor), apixaban (Eliquis, factor Xa inhibitor), betrixaban (Bevyxxa, factor Xa inhibitor), and edoxaban (Savaya, factor Xa inhibitor). DOACs are also referred to as target-specific oral anticoagulants or novel oral anticoagulants (NOACs) or non-vitamin K oral anticoagulants (VKA); however, the term NOAC may be falling out of favor, as NOAC has been mistaken for NO AC (i.e., no anticoagulation) and inadvertently stopped in patients. ${ }^{49}$ The designation DOAC distinguishes these medications from warfarin, which acts as an indirect oral anticoagulant through vitamin-K antagonism, and direct-acting anticoagulants in solution that are given as injections (either intravenous or subcutaneous).

Direct-acting oral anticoagulants as a class have been approved for the following uses: prevention of thromboembolic phenomenon in atrial fibrillation, VTE prevention in patients undergoing hip or knee replacement and in patients hospitalized for acute illness, and as treatment of VTE or PE and prevention of recurrence of VTE or PE. For each drug and approved indication, one or more large phase III studies were performed that included many patients in numerous countries. ${ }^{50-65}$ In general, DOACs (at the approved doses) were found to be noninferior or slightly superior in preventing thromboembolic events compared with the existing standard-of-care in each trial-either warfarin or LMWH. ${ }^{66,67}$ In each of these trials, patients with abnormal hepatic biochemical tests, active liver disease, or cirrhosis were often excluded. Additionally, phase III trials for apixaban, dabigatran, edoxaban, and betrixaban all excluded patients with platelet counts less than 100,000 cells $/ \mu \mathrm{L}$. Rivaroxaban trials did not have a strict platelet threshold, but one did exclude patients with "hepatic disease which is associated with coagulopathy leading to a clinically relevant bleeding risk," which would include those with undiagnosed cirrhosis and likely portal hypertension. ${ }^{59}$

\section{Hepatic Metabolism and Pharmacokinetics of DOACs in Cirrhosis}

Although four of the five currently approved DOACs have the same target-factor $\mathrm{Xa}$-the metabolism and pharmacokinetics (PKs) of these drugs differ (-Table 1). Rivaroxaban is

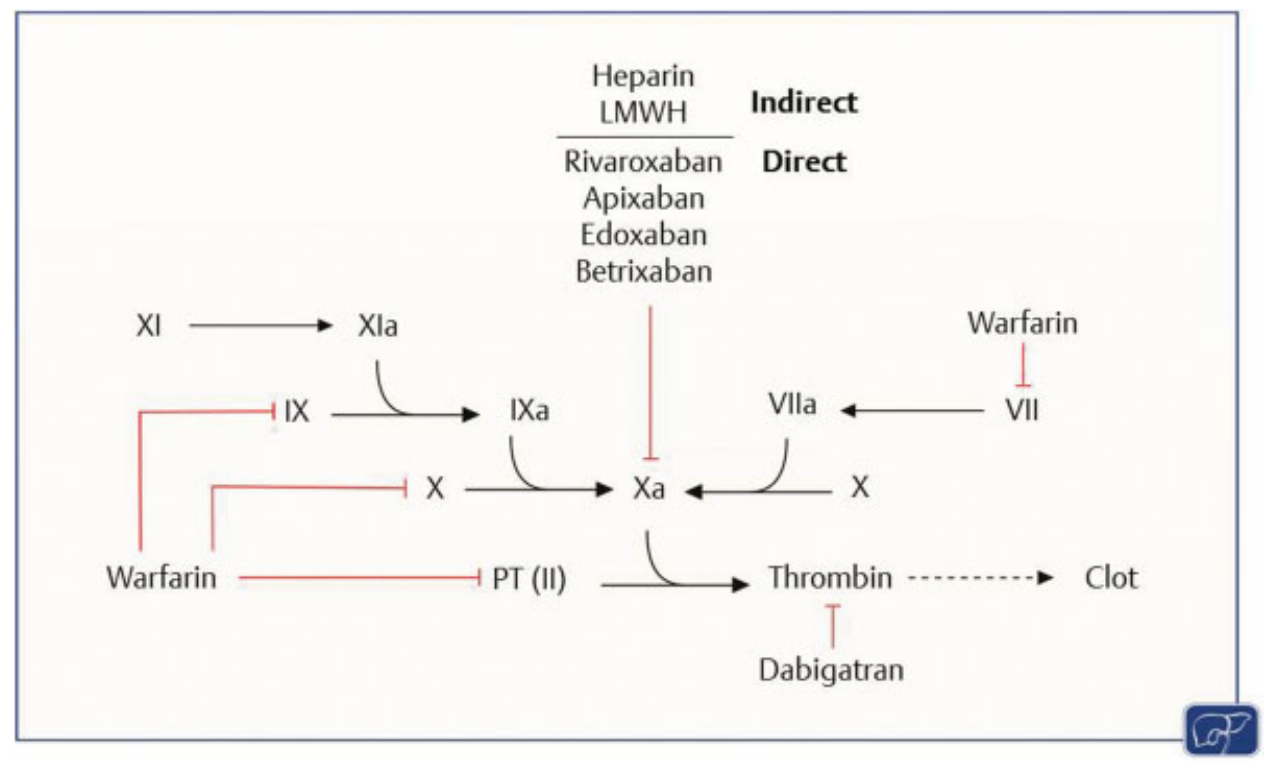

Fig. 2 Sites of action for commonly used anticoagulants. 
Table 1 DOAC hepatic metabolism, pharmacokinetics, and effects on INR

\begin{tabular}{|l|l|l|l|l|l|}
\hline & Rivaroxaban & Apixaban & Edoxaban & Betrixaban & Dabigatran \\
\hline Mechanism of action & $\begin{array}{l}\text { Factor Xa } \\
\text { inhibition }\end{array}$ & $\begin{array}{l}\text { Factor Xa } \\
\text { inhibition }\end{array}$ & $\begin{array}{l}\text { Factor Xa } \\
\text { inhibition }\end{array}$ & $\begin{array}{l}\text { Factor Xa } \\
\text { inhibition }\end{array}$ & $\begin{array}{l}\text { Thrombin } \\
\text { inhibition }\end{array}$ \\
\hline Hepatic metabolism & ++ & +++ & +++ & - & + \\
\hline Peak drug levels $\left(C_{\text {max }}\right)$ & & & & & \\
\hline CTP-A & $\uparrow$ & - & $\downarrow$ & NR & \\
\hline CTP-B & $\uparrow \uparrow$ & - & $\downarrow \downarrow$ & NR & $\downarrow$ \\
\hline Drug exposure (AUC) & & & & NR & \\
\hline CTP-A & - & - & $\downarrow$ & NR & $\downarrow$ \\
\hline CTP-B & $\uparrow$ & - & $\downarrow$ & & \\
\hline Effect on INR & & & NR & NR & $\uparrow$ \\
\hline CTP-A & $\uparrow$ & $\uparrow$ & NR & $\uparrow$ \\
\hline CTP-B & $\uparrow \uparrow$ & $\uparrow$ & & \\
\hline
\end{tabular}

Abbreviation: AUC, area under the curve; CTP, Child-Turcotte-Pugh; DOAC, direct-acting oral anticoagulant; INR, international normalized ratio; NR, not reported.

Note: Arrows signify relative change. Data from Graff and Harder, $2013^{69}$ and Bunchorntavakul and Reddy, $2017 .{ }^{111}$

processed through both the liver and kidneys, with about two-thirds of the drug metabolized by the liver via cytochrome P450 isoenzymes (CYP), to inactive metabolites. ${ }^{68}$ Kubitza et al performed a PK study evaluating a single dose of rivaroxaban in patients with CTP class A and B. ${ }^{68}$ Compared with healthy controls, a single dose of rivaroxaban had slightly increased exposure in CTP-A (area under the curve [AUC]: 1.15), but moderately increased in CTP-B (AUC: 2.27), leading to longer inhibition of factor Xa in CTP-B. Additionally, rivaroxaban led to increases in PT in CTP-B. ${ }^{68}$ Apixaban undergoes both hepatic metabolism (through multiple CYPs) and renal and intestinal excretion. ${ }^{69}$ Peak drug levels of a single dose of $5 \mathrm{mg}$ apixaban were not changed in CTP-A and CTP-B compared with healthy controls; drug exposure was slightly elevated (AUC: 1.03 and 1.09, respectively). ${ }^{69}$ Apixaban leads to increased PT in both CTP-A and CTP-B. ${ }^{69}$

Edoxaban is metabolized in the liver through CYP3A4 and also undergoes renal excretion. ${ }^{70}$ Though requiring significant hepatic metabolism, edoxaban demonstrated decreased peak levels and drug exposure in CTP-A and CTP-B patients compared with healthy controls. ${ }^{71}$ Edoxaban increased PT in healthy volunteers, but data on the effects of PT in patients with cirrhosis is lacking. ${ }^{70}$ Dabigatran does not undergo considerable CYP processing in the liver and is mostly excreted through the kidneys as active dabigatran. ${ }^{69}$ Dabigatran peak levels $\left(C_{\max }\right)$ and exposure (AUC) were slightly lower (but not statistically significant) in CTP-B patients compared with healthy controls after a single dose of $150 \mathrm{mg}$ dabigatran. ${ }^{69}$ Betrixaban varies markedly from the other factor Xa inhibitors in its metabolism, as it is primarily excreted through the intestines after undergoing passage through P-glycoprotein pumps and undergoes minimal hepatic metabolism or renal excretion. ${ }^{72} \mathrm{~A}$ phase I trial evaluating the PKs of betrixaban in CTP-A and CTP-B was completed in early 2018, but results have not yet been released. ${ }^{73}$ There are no studies to date with any of the
DOACs evaluating the PKs in patients with CTP-C. Rivaroxaban, apixaban, dabigatran, and betrixaban have undergone PK studies in CTP-B patients (though for betrixaban has not yet been published). ${ }^{68,69,71,73}$

\section{DOACs for Treatment of PVT in Cirrhosis}

Direct-acting oral anticoagulants have not been extensively studied in patients with cirrhosis. A few studies have investigated the safety and efficacy of DOACs in patients with cirrhosis with indications for anticoagulant therapy including atrial fibrillation, VTE, and PVT (-Table 2). DOACs were noted to have similar safety profiles as traditional anticoagulants (i.e., warfarin, heparin, and LMWH) in these groups, demonstrated by the comparable rates of bleeding complications in patients receiving DOACs and those receiving traditional anticoagulants. ${ }^{74-82}$ Numerous case studies have reported on the use of DOACs in patients with cirrhosis for the treatment or prevention of recurrence of PVT. In the majority of cases, treating portal system VTE (including partial/complete PVT, SMV, or both) with DOACs successfully resulted in partial/complete resolution of the thrombus. ${ }^{83-88}$

While there has not yet been a randomized control trial comparing the safety and efficacy of DOACs versus traditional anticoagulation for the treatment of PVT in cirrhosis, Nagaoki et al recently published a historical comparison at a single institution comparing maintenance treatment of edoxaban and warfarin in cirrhotic patients with acute PVT. ${ }^{78}$ All patients received 2 weeks of intravenous danaparoid prior to OAC. Patients diagnosed prior to November 2014 received warfarin therapy $(n=30)$; those afterwards received edoxaban $(n=20)$, with patients receiving OAC for up to 6 months. A significantly larger percentage of patients receiving edoxaban compared with warfarin achieved complete resolution of PVT (70\% vs. $20 \%) .{ }^{78}$ Additionally, a smaller percentage of patients receiving edoxaban 


\begin{tabular}{|c|c|c|c|c|}
\hline$\frac{\vec{i}}{\stackrel{u}{n}}$ & 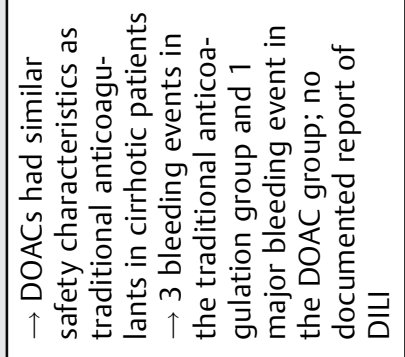 & 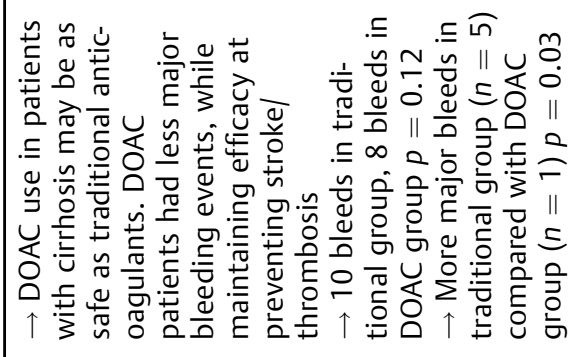 & 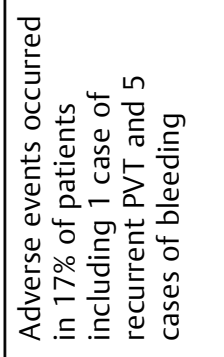 & 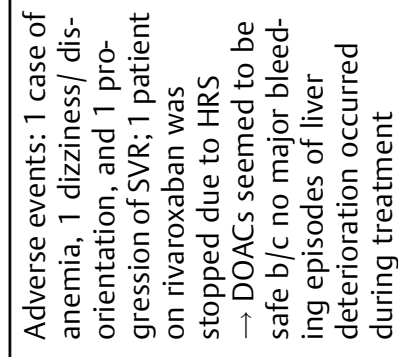 \\
\hline & 1 & 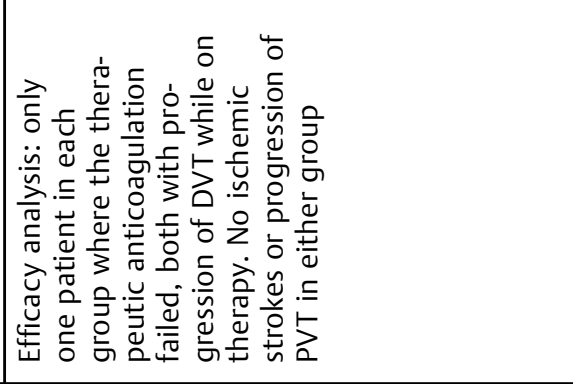 & 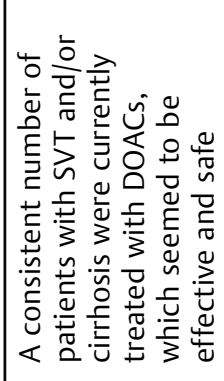 & I \\
\hline 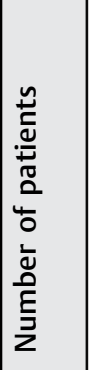 & 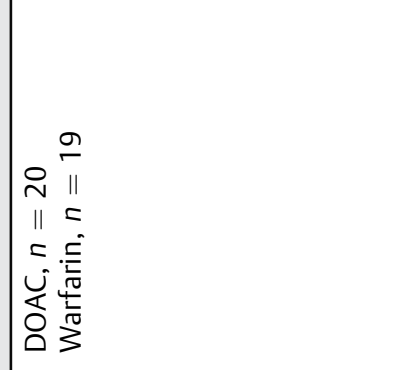 & 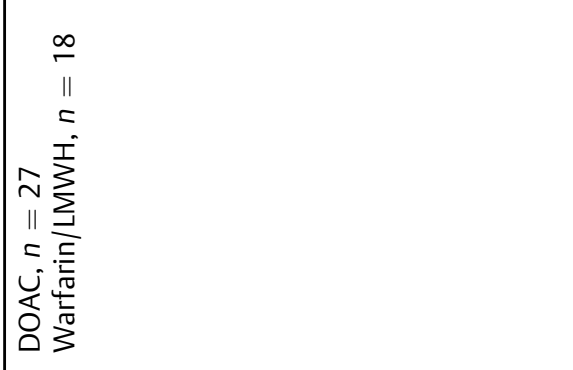 & 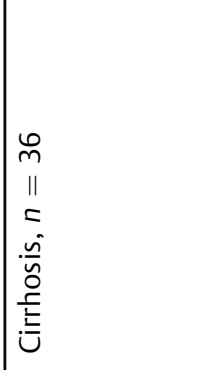 & 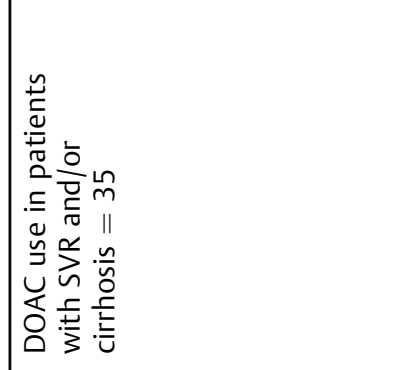 \\
\hline 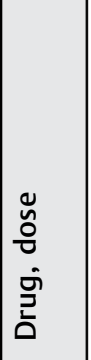 & 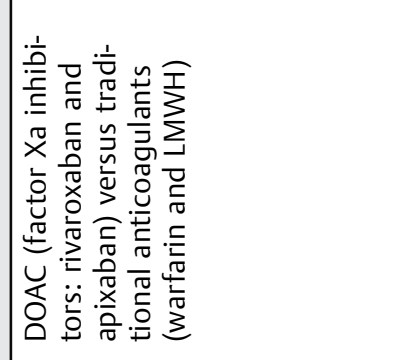 & 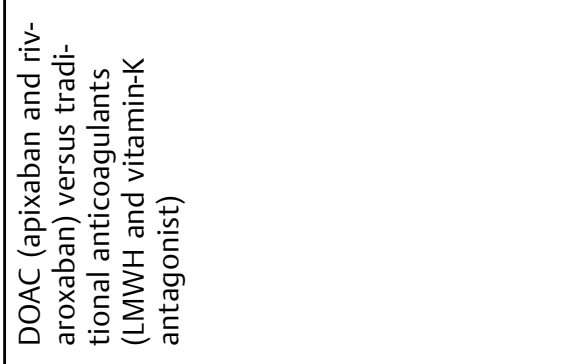 & 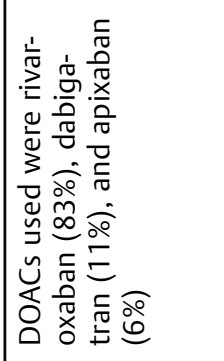 & 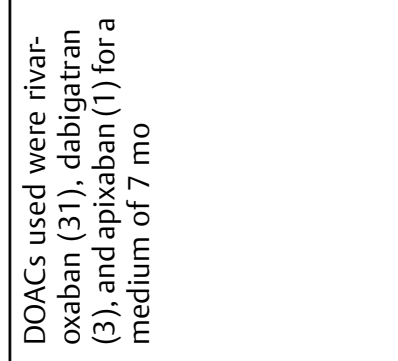 \\
\hline 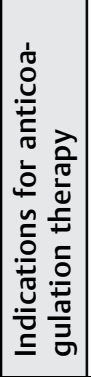 & 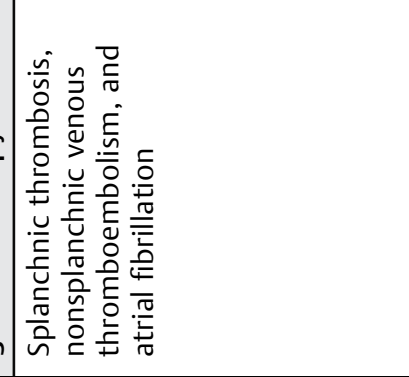 & 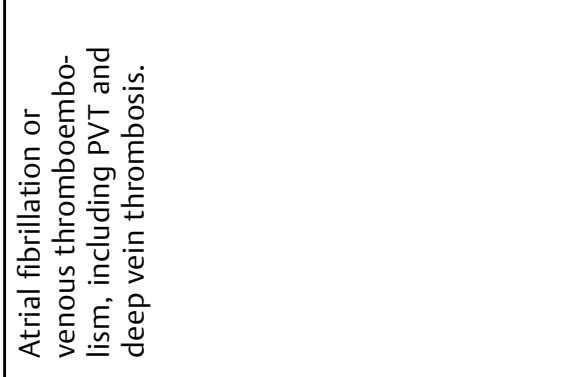 & 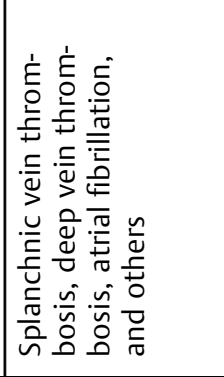 & 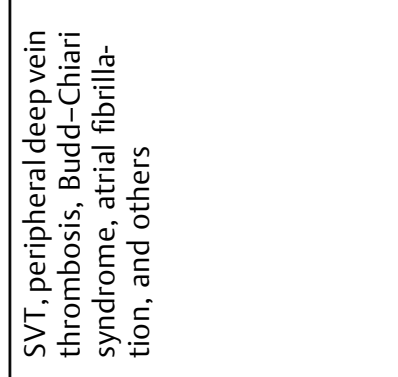 \\
\hline 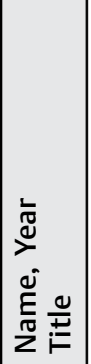 & 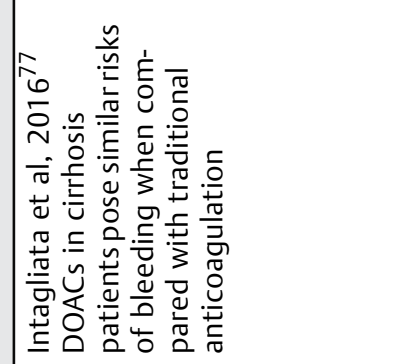 & 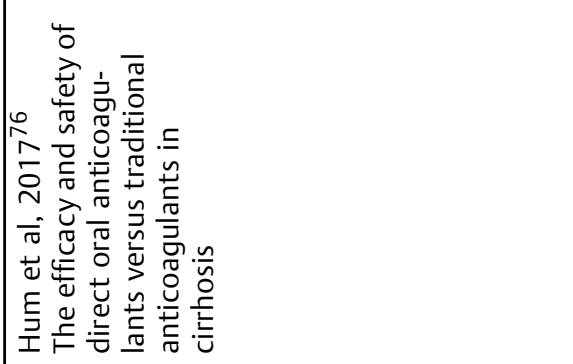 & 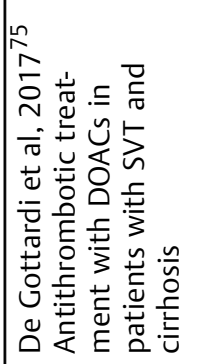 & 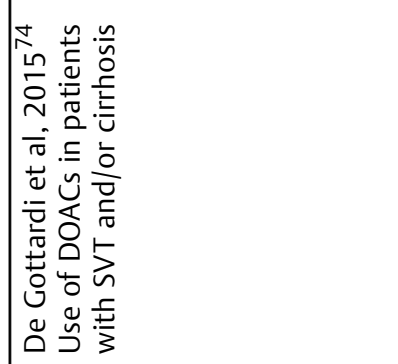 \\
\hline
\end{tabular}




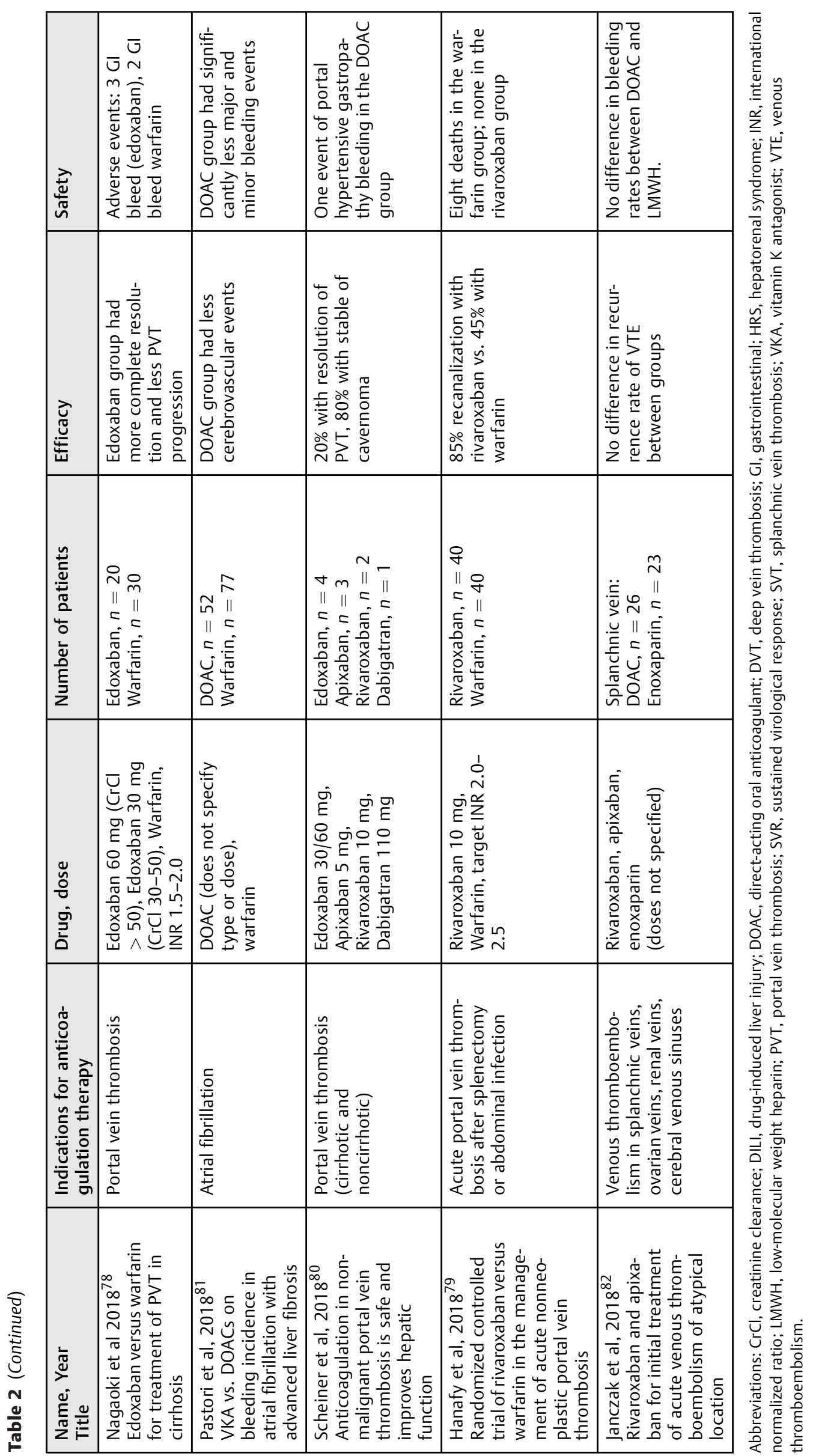


had progression of PVT (5\% vs. $47 \%$ ). Only five patients had major bleeding events; the study was not powered to evaluate for a difference in bleeding rate. Hanafy et al recently reported their findings comparing rivaroxaban to warfarin for the treatment of acute PVT in a unique Egyptian population with hepatitis $\mathrm{C}$ cirrhosis that had mostly undergone splenectomy for symptomatic hypersplenism within 1 week prior to enrollment. ${ }^{79}$ The patients receiving rivaroxaban achieved recanalization of the portal vein at much higher rates (34/40) compared with those receiving warfarin (18/ $40) .{ }^{79}$ There were no reported hepatic decompensations or death in the rivaroxaban group, while patients in the warfarin group experienced ascites, gastrointestinal bleeding, encephalopathy, and death. ${ }^{79}$

The EASL PVT guidelines have a section devoted to treating PVT in cirrhosis with DOACs, but recommend caution given the paucity of data on this subject and the reported cases of hepatotoxicity in patients on rivaroxaban. ${ }^{14}$ Currently, clinical trials are being conducted to investigate the safety and efficacy of rivaroxaban for the primary and secondary prevention of PVT in cirrhotic patients. ${ }^{89,90}$ These trials are evaluating the prophylactic use of DOACs to prevent initial or recurrent PVT by measuring the incidence of thromboembolic events, while also monitoring for safety outcomes, providing more insight into the efficacy/safety of DOAC therapy in patients with cirrhosis and help guide clinical practice. - Table 3 summarizes the salient advantages and disadvantages of three anticoagulant classesDOACs, LMWH, and VKA. While in the Villa et al study no patients in the enoxaparin arm developed a PVT, it remains to be seen how many PVTs could be prevented with prophylactic use of DOACs. Ponziani et al reported on a patient with cryptogenic cirrhosis that developed a PVT while on rivaroxaban for atrial fibrillation. This patient was subsequently switched to LMWH, but the PVT underwent cavernous transformation despite therapy. ${ }^{91}$

\section{DOACs in Pregnancy and Lactation}

Direct-acting oral anticoagulants are not currently recommended for use during pregnancy; this is unlikely to change given the experience and safety of LMWH, which does not cross the placenta. ${ }^{92}$ Bapat et al evaluated the transplacental PKs of dabigatran, rivaroxaban, and apixaban using a dual perfusion ex vivo full-term human placenta model. ${ }^{93-95}$ Dabigatran crossed into the fetal circulation slowly, reaching $17 \%$ of the maternal levels after 3 hours. ${ }^{93}$ On the other hand, rivaroxaban and apixaban moved quickly into the fetal circulation in this model, reaching $69 \%$ and $77 \%$, respectively, of the maternal circulation drug levels at 3 hours. ${ }^{94,95}$ Hoeltzenbein et al composed a case series of outcomes in pregnant patients exposed to rivaroxaban. ${ }^{96}$ All women in this series discontinued rivaroxaban after learning of their pregnancy. ${ }^{96}$ of the 37 pregnancies, there were 23 live births; one had severe congenital cardiac malformation (electively terminated) in a patient with systemic lupus erythematosus on numerous other medications that had a history of a fetal cardiac

Table 3 Comparison of different anticoagulants for PVT in cirrhosis

\begin{tabular}{|c|c|c|c|}
\hline & DOACs & LMWH & Warfarin \\
\hline Safety & $\begin{array}{l}\text { Appear as safe as warfarin } \\
\text { and LMWH }\end{array}$ & $\begin{array}{l}\text { Safety risks well- } \\
\text { documented }\end{array}$ & $\begin{array}{l}\text { Safety risks } \\
\text { well-documented }\end{array}$ \\
\hline Clinical experience & $\begin{array}{l}\text { Short track record: } \\
\text { Approved in } 2010 \\
\text { (dabigatran) }\end{array}$ & $\begin{array}{l}\text { Long track record: } \\
\text { Approved in } 1993\end{array}$ & $\begin{array}{l}\text { Longest track record: } \\
\text { Approved in } 1954\end{array}$ \\
\hline Efficacy & $\begin{array}{l}\text { May be more effective than } \\
\text { warfarin for PVT resolution }\end{array}$ & $\begin{array}{l}\text { May be more effective than } \\
\text { warfarin for PVT resolution }\end{array}$ & \\
\hline Monitoring & $\begin{array}{l}\text { Marketed as not necessary, } \\
\text { but more information is } \\
\text { needed }\end{array}$ & Not necessary & Lifelong \\
\hline Wash out period & $\sim 2 \mathrm{~d}$ & $\sim 2-3 d$ & $\sim 5-7 \mathrm{~d}$ \\
\hline FDA-approved for indication & No & No & No \\
\hline Antidote & $\begin{array}{l}\text { Expensive and not widely } \\
\text { available }\end{array}$ & $\begin{array}{l}\text { Expensive and not widely } \\
\text { available }\end{array}$ & $\begin{array}{l}\text { Cheap antidote and widely } \\
\text { available }\end{array}$ \\
\hline Route of administration & Oral & Injection & Oral \\
\hline $\begin{array}{l}\text { Pharmacokinetic studies in } \\
\text { cirrhosis published }\end{array}$ & Yes & No & No \\
\hline Hepatotoxicity & $\begin{array}{l}\text { Rates vary with DOAC- } \\
\text { highest with rivaroxaban }\end{array}$ & Extremely rare & Rare \\
\hline $\begin{array}{l}\text { Antifibrotic effects and } \\
\text { evidence }\end{array}$ & Possible, animal studies & Possible, clinical trial & Possible, animal studies \\
\hline
\end{tabular}

Abbreviations: DOAC, direct-acting oral anticoagulant; FDA, Food and Drug Administration; LMWH, low-molecular-weight heparin; PVT, portal vein thrombosis. 
malformation (electively terminated) in a previous pregnancy prior to taking rivaroxaban. ${ }^{96}$

Compiling data from numerous types of sources (literature, study groups, government agency pharmacovigilance, and industry pharmacovigilance), Beyer-Westendorf et al sought to evaluate the pregnancy outcomes in women exposed to DOACs during pregnancy. ${ }^{97}$ of the 233 reported DOAC exposures in pregnancy, only $59 \%(n=137)$ had an available outcome, with about half $(n=67)$ of those leading to live births. ${ }^{97}$ Most women in this cohort were prescribed DOACs for the treatment of VTE and discontinued the DOAC within 2 months of becoming pregnant. ${ }^{97}$ The miscarriage rate for pregnant women on DOACs was $22 \%$, which is similar to the general population, and less than with warfarin (30\%). ${ }^{97}$ The authors noted three possible drug-related anatomical abnormalities, but were unable to deduce a pattern and were unable to provide new recommendations based on their observations.

Direct-acting oral anticoagulants are also not recommended for use in lactating women. A preclinical rat model using radiolabeled apixaban demonstrated that apixaban reached higher concentration in milk than in blood or plasma, with peak milk concentrations at 6 hours postingestion. ${ }^{98}$ The authors estimated that baby rats could receive up to $10 \%$ of the maternal dose through breast milk ingestion. ${ }^{98}$ Wiesen et al capitalized on a rare situation when a lactating woman was diagnosed with a lower extremity VTE in their hospital. ${ }^{99}$ The patient had ceased breastfeeding due a postpartum cardiomyopathy and was treated initially with enoxaparin followed by rivaroxaban. ${ }^{99}$ During weaning, breast milk samples were collected for analysis of rivaroxaban levels. ${ }^{99}$ Rivaroxaban concentration in the milk reached $40 \%$ of the plasma drug concentration, with the estimated relative infant dose to be $1.3 \%$-well below the proposed acceptable $10 \%$ exposure concentration. ${ }^{99}$ It remains to be seen whether some DOACs will eventually be determined to be safe for use in lactating women.

\section{Direct-Acting Oral Anticoagulant Safety}

\section{Direct-Acting Oral Anticoagulants and Bleeding}

In addition to the efficacy of DOACs in preventing primary or secondary VTE and emboli, a primary concern of these medications is the bleeding risk. Ruff et al composed a metaanalysis of four phase III randomized trials in which DOACs (rivaroxaban, apixaban, edoxaban, and dabigatran) were evaluated for the prevention of embolic events in patients ( $n=71,683)$ with atrial fibrillation. ${ }^{100}$ In each of these trials, warfarin was used as the standard-of-care comparison. Overall, patients receiving DOACs in these trials experienced less hemorrhagic stroke and intracranial bleeding, translating into improved mortality compared with those receiving warfarin. ${ }^{100}$ However, patients receiving warfarin experienced less gastrointestinal bleeding than those randomized to DOACs, while those on DOACs experienced fewer composite major bleeding events. ${ }^{100}$

More recently, large-scale postmarketing studies using large health care databases (national health care or insurance systems) comparing the safety of DOACs to warfarin have provided real-world data. Using the MarketScan database, Coleman et al found that apixaban and dabigatran performed similarly to warfarin in patients with atrial fibrillation and a prior ischemic stroke or transient ischemic attack (TIAs) while on anticoagulation for secondary prophylaxis, in regards to stroke prevention and major bleeding risk. ${ }^{101}$ Patients on rivaroxaban had suffered fewer strokes and TIAs than those on warfarin without an increase in bleeding. ${ }^{101}$ Though also using the MarketScan database, Lip et al found slightly different outcomes for major bleeding events in patients on anticoagulation with DOACs compared with warfarin for atrial fibrillation. ${ }^{102}$ Lip et al reported a decreased major bleeding risk with apixaban compared with warfarin, while dabigatran and rivaroxaban performed similarly to warfarin. ${ }^{102}$ Jacobs et al described decreased major bleeding events, strokes, and death in a matched cohort of patients receiving DOACs compared with warfarin in the Intermountain Healthcare system. ${ }^{103}$

Health care providers, not uncommonly, encounter patients on anticoagulation in the setting of a gastrointestinal bleed. A phase III study evaluating dabigatran for patients with atrial fibrillation found a small, but significant increase in gastrointestinal bleeding in patients receiving the higher dose of dabigatran (150 mg twice daily) compared with those receiving warfarin or the lower dose of dabigatran (110 mg twice daily) ${ }^{55}$ In addition, patients receiving either dose of dabigatran had higher rates of gastrointestinal symptoms and dyspepsia, compared with warfarin. ${ }^{55}$ The authors point out that the increase in gastrointestinal side effects is likely a result of the dabigatran formulation. ${ }^{55} \mathrm{~A}$ low $\mathrm{pH}$ is needed for dabigatran absorption; to decrease the $\mathrm{pH}$ around the drug, dabigatran pellets are wrapped in tartaric acid, which can lead to dyspepsia or ulcerations at any point in the gastrointestinal tract. ${ }^{55}$ As a result of the wrapped formulation, dabigatran cannot be crushed, unlike other DOACs which are not dependent upon an acidic environment.

Two studies using United States insurance claims databases found no significant difference overall in DOACs (rivaroxaban and dabigatran) compared with warfarin in gastrointestinal bleeding events, but cautioned that patients older than 75 years on DOACs had increased gastrointestinal bleeding rates compared with patients older than 75 years on warfarin. ${ }^{104,105}$ Cangemi et al, using the Veterans Affairs database, observed much lower rates of gastrointestinal bleeding among patients receiving DOACs than those on warfarin. ${ }^{106}$ Therapeutic endoscopy inherently carries a higher bleeding rate than diagnostic endoscopy. Nagata et al employed the Japanese national health care system claims database to evaluate postprocedure complications after therapeutic endoscopy for those on anticoagulation. ${ }^{107}$ Patients on DOACs experienced less postendoscopy bleeding than those on warfarin; VTE and mortality did not differ between the two groups. ${ }^{107}$ It is important to note that none of the studies listed above contained enough patients with cirrhosis to make additional claims for the cirrhosis subgroup. 


\section{Direct-Acting Oral Anticoagulants and Monitoring}

While the main appeal of DOACs has been the claim that drug monitoring is not necessary, there has been some controversy over this issue. Reilly et al reported increased bleeding rates and decreased stroke rates among patients with higher plasma concentrations of dabigatran; those who tended to have higher plasma concentrations of dabigatran were older, had worse renal function, weighed less, and were female. ${ }^{108}$ The corollary was also true-those patients with lower dabigatran plasma concentrations were more likely to have an ischemic stroke and less likely to have major bleeding. ${ }^{108}$ However, it is unknown if hepatic impairment would further alter dabigatran plasma concentration given its lack of metabolism by the liver. Similar studies evaluating the effect of plasma concentration on serious adverse events from large trials have not been published for other DOACs, but that does not mean that it is not a concern.

\section{Direct-Acting Oral Anticoagulants and Drug-Induced Liver Injury}

Aside from bleeding events, another safety concern is of drug-induced liver injury (DILI) associated with DOACs. Caldeira et al performed a meta-analysis of 29 large-scale randomized controlled trials $(n=152,116)$ comparing DOACs to standard-of-care and found no significant difference in DILI events among the groups. ${ }^{109}$ In fact, patients receiving DOACs had significantly fewer instances of elevated hepatic biochemical tests compared with LMWH. ${ }^{109}$ However, real-world data suggest that rivaroxaban may have higher rates of DILI compared with other DOACs and warfarin. ${ }^{110}$ Concomitant use of statins, amiodarone, and acetaminophen were reported in about two-fifths of rivaroxaban-attributable DILI. ${ }^{111}$ Rivaroxaban-induced liver injury is likely drug-specific rather than class-specific, exemplified by a case in which a patient with atrial fibrillation had a severe hepatocellular injury with development of hepatic steatosis after initiation of rivaroxaban that resolved with a switch to apixaban. ${ }^{112}$ Dabigatran, apixaban, and edoxaban have also been associated with DILI, though less reported than rivaroxaban. ${ }^{111}$

\section{Direct-Acting Oral Anticoagulant Antidotes}

A common reason for clinicians not to switch a patient from warfarin to DOAC has been the concern about antidote for major bleeding associated with DOACs. The antidote for warfarin-vitamin $\mathrm{K}$-has been available longer than warfarin itself. For patients on warfarin with significant bleeding that does stop with vitamin Kadministration or bleeding that is located at a critical site or is life-threatening, the most recent multidisciplinary guidelines recommend administration of four-factor PT complex (4F-PCC) concentrate over plasma (fresh frozen, frozen, or thawed) given smaller volume of administration and the rapidity of INR correction with 4F-PCC over plasma. ${ }^{113}$ Idarucizumab, a monoclonal antibody fragment that binds dabigatran, was the first FDAapproved corrective specifically designed for any DOAC. ${ }^{114}$ Idarucizumab was approved in 2015 based on an interim analysis demonstrating rapid normalization of dilute throm- bin time or ecarin clotting time in patients requiring reversal of dabigatran-induced anticoagulation due to serious bleeding or need for an urgent procedure. ${ }^{114}$ The full cohort analysis of idarucizumab for reversal of dabigatran, published in 2017, confirmed the interim findings. ${ }^{115}$ Most recently, in May 2018, andexanet (a recombinant factor Xa protein decoy) was approved as an antidote to factor $\mathrm{Xa}$ inhibitors rivaroxaban and apixaban based on an open-label study evaluating hemostasis in patients on factor Xa inhibitors with major bleeding event. ${ }^{116}$ While andexanet is currently approved only for reversal of rivaroxaban and apixaban, a trial is ongoing evaluating its effects on enoxaparin and edoxaban as well. In cases when a specific antidote for any anticoagulant is not available or is insufficient in providing necessary hemostasis, 4F-PCC is the recommended treatment; if a DOAC has been ingested within 4 hours of presentation, activated charcoal should also be considered. ${ }^{113}$ While it is highly likely that idarucizumab and andexanet provide necessary hemostasis in emergency settings for patients with cirrhosis, the rate of serious adverse events, particularly splanchnic thrombosis, are not known and will need to be followed through postmarketing registries.

\section{Conclusion}

It is understandable that the gastroenterology and hepatology community has not quickly embraced DOACs. However, this delay in DOAC adoption does not mean that DOACs are inferior to traditional anticoagulants; simply that more data are needed on the safety of DOACs in cirrhosis, although warfarin and LMWH became standard of care with limited data and poorly done studies. Patients with cirrhosis are at increased risk of bleeding compared with the general population and often have decreased platelet counts as a result of their liver disease. Interestingly, none of the currently FDAapproved DOACs mention platelet thresholds or warning for patients with thrombocytopenia in their prescribing information despite excluding these patients in the large trials. Given the tremendous variability in the liver's role in metabolism of each DOAC, it is likely that some DOACs may be safer for those with cirrhosis than others. PK studies of rivaroxaban demonstrated increased drug exposure among CTP-B patients, but other studies have suggested possible decreased exposure of rivaroxaban in cirrhosis. ${ }^{117,118}$ Additionally, rivaroxaban has higher reported rates of hepatotoxicity than other DOACs. These two factors suggest that rivaroxaban is not the ideal DOAC for patients with cirrhosis. There has not yet been a PK study reported for CTP-C patients for any DOAC. For those with compensated cirrhosis (CTP-A), well-designed randomized control trials are needed to evaluate the safety and efficacy of DOACs for the treatment of PVT. It does appear that there is consensus on screening and treatment of esophageal varices prior to initiation of anticoagulation for PVT, but the best timeframe and method for variceal treatment prior to initiation of DOAC will need to be determined. Since the progression of PVT has been linked to increased hepatic decompensation events and even 
mortality, prompt treatment of PVT with anticoagulant therapy can be beneficial for certain patients with cirrhosis.

While some studies demonstrate the possible benefits of anticoagulants in the setting of cirrhosis to prevent PVT, the field needs to design more trials to evaluate the effects of prophylactic anticoagulation in patients who are at risk for developing PVT. Importantly, the field needs to clearly define which patients are at the highest risk for the development of PVT, and define what the absolute contraindications for anticoagulation in the setting of cirrhosis are. Child-Pugh $\mathrm{B}$ and $\mathrm{C}$ decompensated state is most likely to benefit from anticoagulant therapy, although this will likely depend on flow state and preexisting prothrombotic tendencies. However, randomized controlled trials are necessary to help set treatment and prophylaxis guidelines. Currently, there are multiple DOACs that are available that are used to prevent and treat thrombotic events. The data for their use in patients with cirrhosis are relatively sparse while the preliminary experience suggests that they are safe and effective (-Table 3). There is no evidence to suggest any particular DOAC for patients with CTP-A cirrhosis. Based on scant data from several clinical trials, and on pharmacodynamics properties, it appears that apixaban would be the preferred DOAC in patients with CTP-B cirrhosis. Apixaban has a favorable DILI profile compared with other DOACs and has minimal changes in its pharmacodynamics in CTP-B patients. Recommendations for use of DOACs in patients with cirrhosisassociated thrombocytopenia are based solely on expert opinion given the paucity of data in this group. We are reluctant to initiate DOACs in a patient with a cirrhosisassociated PVT if the platelet count is less than 50,000 cells/ $\mu \mathrm{L}$ and use considerable caution if the platelet count is between 50,000 and 80,000 cells $/ \mu \mathrm{L}$.

The traditional experience with warfarin and LMWH is being vigorously challenged by both the patient and treating community and there is a considerable push toward the use of DOACs given their safety and efficacy, and the relative less need for monitoring of adequacy of anticoagulation, in patients with cirrhosis. While we recommend well-designed and randomized trials to demonstrate their safety and efficacy so that we can establish concrete guidelines on their use in those with cirrhosis who have thrombotic events or who are at-risk for clotting manifestations, it is unlikely that we will see properly done trials comparing DAOCs with LMWH and warfarin with the intention of assessing their comparative safety and efficacy. Thus, as it stands now and with the data available, it is reasonable to consider DOACs as an alternative in patients with compensated cirrhosis and without severe thrombocytopenia, both as prophylaxis and as treatment of thrombosis.

\section{Main Concepts and Learning Points}

- While the large trials that led to the approval of DOACs excluded patients with cirrhosis, based on limited studies and pharmacokinetics, DOACs appear to be as safe and efficacious as traditional anticoagulants in patients with compensated cirrhosis, while more studies are needed in patients with decompensated cirrhosis to determine the optimal drug and dose in this patient population.

- A small number of trials and case series demonstrate that DOACs are effective in the treatment of acute portal vein thrombosis and may have superior efficacy compared with vitamin-K antagonists.

- Preclinical studies suggest antifibrotic effects of thrombin and factor Xa inhibition in liver disease models, indicating that there may be an additional role for DOACs in patients with cirrhosis aside from treatment of splanchnic venous thrombosis and thromboembolism.

\section{Conflicts of Interest}

E.M.W. has no disclosures. J.P. has no disclosures. K.R.R. discloses research support (paid to the University of Pennsylvania) from AbbVie, Merck, Gilead, and BristolMyers Squibb. K.R.R. is also on the Scientific Advisory Board for AbbVie, Gilead, and Merck on Hepatitis C therapeutic area.

\section{References}

1 Tripodi A, Mannucci PM. The coagulopathy of chronic liver disease. N Engl J Med 2011;365(02):147-156

2 Sarin SK, Philips CA, Kamath PS, et al. Toward a comprehensive new classification of portal vein thrombosis in patients with cirrhosis. Gastroenterology 2016;151(04):574-577.e3

3 Kumar A, Sharma P, Arora A. Review article: portal vein obstruction-epidemiology, pathogenesis, natural history, prognosis and treatment. Aliment Pharmacol Ther 2015;41(03): 276-292

4 Runyon BA; AASLD. Introduction to the revised American Association for the Study of Liver Diseases Practice Guideline management of adult patients with ascites due to cirrhosis 2012. Hepatology 2013;57(04):1651-1653

5 Garcia-Tsao G, Abraldes JG, Berzigotti A, Bosch J. Portal hypertensive bleeding in cirrhosis: risk stratification, diagnosis, and management: 2016 practice guidance by the American Association for the Study of Liver Diseases. Hepatology 2017;65(01): 310-335

6 Nery F, Chevret S, Condat B, et al; Groupe d'Etude et de Traitement du Carcinome Hépatocellulaire. Causes and consequences of portal vein thrombosis in 1,243 patients with cirrhosis: results of a longitudinal study. Hepatology 2015;61(02):660-667

7 Tsochatzis EA, Senzolo M, Germani G, Gatt A, Burroughs AK. Systematic review: portal vein thrombosis in cirrhosis. Aliment Pharmacol Ther 2010;31(03):366-374

8 Amitrano L, Guardascione MA, Brancaccio V, et al. Risk factors and clinical presentation of portal vein thrombosis in patients with liver cirrhosis. J Hepatol 2004;40(05):736-741

9 Qi X, De Stefano V, Wang J, et al. Prevalence of inherited antithrombin, protein $C$, and protein $S$ deficiencies in portal vein system thrombosis and Budd-Chiari syndrome: a systematic review and meta-analysis of observational studies. J Gastroenterol Hepatol 2013;28(03):432-442

10 Zocco MA, Di Stasio E, De Cristofaro R, et al. Thrombotic risk factors in patients with liver cirrhosis: correlation with MELD scoring system and portal vein thrombosis development. J Hepatol 2009;51(04):682-689

11 Girleanu I, Stanciu C, Cojocariu C, Boiculese L, Singeap AM, Trifan A. Natural course of nonmalignant partial portal vein thrombosis in cirrhotic patients. Saudi J Gastroenterol 2014;20 (05):288-292 
12 Luca A, Caruso S, Milazzo M, et al. Natural course of extrahepatic nonmalignant partial portal vein thrombosis in patients with cirrhosis. Radiology 2012;265(01):124-132

13 DeLeve LD, Valla DC, Garcia-Tsao G; American Association for the Study Liver Diseases. Vascular disorders of the liver. Hepatology 2009;49(05):1729-1764

14 Garcia-Pagán JC, Buscarini E, Janssen HLA, et al; European Association for the Study of the Liver. Electronic address: easloffice@easloffice.eu. EASL Clinical Practice Guidelines: vascular diseases of the liver. J Hepatol 2016;64(01):179-202

15 Loffredo L, Pastori D, Farcomeni A, Violi F. Effects of anticoagulants in patients with cirrhosis and portal vein thrombosis: a systematic review and meta-analysis. Gastroenterology 2017; 153(02):480-487.e1

16 Yerdel MA, Gunson B, Mirza D, et al. Portal vein thrombosis in adults undergoing liver transplantation: risk factors, screening, management, and outcome. Transplantation 2000;69(09): 1873-1881

17 Kim SJ, Kim DG, Park JH, et al. Clinical analysis of living donor liver transplantation in patients with portal vein thrombosis. Clin Transplant 2011;25(01):111-118

18 D'Amico G, Tarantino G, Spaggiari M, et al. Multiple ways to manage portal thrombosis during liver transplantation: surgical techniques and outcomes. Transplant Proc 2013;45(07): 2692-2699

19 Gao PJ, Gao J, Li Z, Hu ZP, Leng XS, Zhu JY. Liver transplantation in adults with portal vein thrombosis: data from the China Liver Transplant Registry. Clin Res Hepatol Gastroenterol 2016;40 (03):327-332

$20 \mathrm{Wu} \mathrm{H}$, Nguyen GC. Liver cirrhosis is associated with venous thromboembolism among hospitalized patients in a nationwide US study. Clin Gastroenterol Hepatol 2010;8(09):800-805

21 Ali M, Ananthakrishnan AN, McGinley EL, Saeian K. Deep vein thrombosis and pulmonary embolism in hospitalized patients with cirrhosis: a nationwide analysis. Dig Dis Sci 2011;56(07): 2152-2159

22 Saleh T, Matta F, Alali F, Stein PD. Venous thromboembolism with chronic liver disease. Am J Med 2011;124(01):64-68

23 Northup PG, McMahon MM, Ruhl AP, et al. Coagulopathy does not fully protect hospitalized cirrhosis patients from peripheral venous thromboembolism. Am J Gastroenterol 2006;101(07): 1524-1528, quiz 1680

24 Anthony Lizarraga W, Dalia S, Reinert SE, Schiffman FJ. Venous thrombosis in patients with chronic liver disease. Blood Coagul Fibrinolysis 2010;21(05):431-435

25 Gulley D, Teal E, Suvannasankha A, Chalasani N, Liangpunsakul S. Deep vein thrombosis and pulmonary embolism in cirrhosis patients. Dig Dis Sci 2008;53(11):3012-3017

26 Walsh KA, Lewis DA, Clifford TM, et al. Risk factors for venous thromboembolism in patients with chronic liver disease. Ann Pharmacother 2013;47(03):333-339

27 Dabbagh O, Oza A, Prakash S, Sunna R, Saettele TM. Coagulopathy does not protect against venous thromboembolism in hospitalized patients with chronic liver disease. Chest 2010;137(05): 1145-1149

28 Søgaard KK, Horváth-Puhó E, Montomoli J, Vilstrup H, Sørensen HT. Cirrhosis is associated with an increased 30-day mortality after venous thromboembolism. Clin Transl Gastroenterol 2015; 6(June):e97

29 Kremers RMW, Kleinegris M-C, Ninivaggi M, et al. Decreased prothrombin conversion and reduced thrombin inactivation explain rebalanced thrombin generation in liver cirrhosis. PLoS One 2017;12(05):e0177020

30 Marra F, DeFranco R, Grappone C, et al. Expression of the thrombin receptor in human liver: up-regulation during acute and chronic injury. Hepatology 1998;27(02):462-471

31 Marra F, Grandaliano G, Valente AJ, Abboud HE. Thrombin stimulates proliferation of liver fat-storing cells and expression of monocyte chemotactic protein-1: potential role in liver injury. Hepatology 1995;22(03):780-787

32 Bogatkevich GS, Ludwicka-Bradley A, Nietert PJ, Akter T, van Ryn J, Silver RM. Antiinflammatory and antifibrotic effects of the oral direct thrombin inhibitor dabigatran etexilate in a murine model of interstitial lung disease. Arthritis Rheum 2011;63(05): 1416-1425

33 Kassel KM, Sullivan BP, Cui W, Copple BL, Luyendyk JP. Therapeutic administration of the direct thrombin inhibitor argatroban reduces hepatic inflammation in mice with established fatty liver disease. Am J Pathol 2012;181(04):1287-1295

34 Kopec AK, Joshi N, Towery KL, et al. Thrombin inhibition with dabigatran protects against high-fat diet-induced fatty liver disease in mice. J Pharmacol Exp Ther 2014;351(02):288-297

35 Mehta H, Mashiko S, Goulet P-O, et al. Dabigatran aggravates topoisomerase I peptide-loaded dendritic cells-induced lung and skin fibrosis. Clin Exp Rheumatol 2017;35(04, Suppl 106):35-39

36 Abe W, Ikejima K, Lang T, et al. Low molecular weight heparin prevents hepatic fibrogenesis caused by carbon tetrachloride in the rat. J Hepatol 2007;46(02):286-294

37 Assy N, Hussein O, Khalil A, et al. The beneficial effect of aspirin and enoxaparin on fibrosis progression and regenerative activity in a rat model of cirrhosis. Dig Dis Sci 2007;52(05):1187-1193

38 Cerini F, Vilaseca M, Lafoz E, et al. Enoxaparin reduces hepatic vascular resistance and portal pressure in cirrhotic rats. J Hepatol 2016;64(04):834-842

39 Fortea JI, Zipprich A, Fernandez-Mena C, et al. Enoxaparin does not ameliorate liver fibrosis or portal hypertension in rats with advanced cirrhosis. Liver Int 2018;38(01):102-112

40 Vilaseca M, García-Calderó H, Lafoz E, et al. The anticoagulant rivaroxaban lowers portal hypertension in cirrhotic rats mainly by deactivating hepatic stellate cells. Hepatology 2017;65(06): 2031-2044

41 Oken OF, Yildirim AO, Gulcek M, et al. The effect of prophylactic dose of a low molecular weight heparin on skin wound healing of rats. Acta Cir Bras 2009;24(06):471-475

42 Ferlitsch M, Reiberger T, Hoke M, et al. von Willebrand factor as new noninvasive predictor of portal hypertension, decompensation and mortality in patients with liver cirrhosis. Hepatology 2012;56(04):1439-1447

43 Prasanna KS, Goel A, Amirtharaj GJ, et al. Plasma von Willebrand factor levels predict in-hospital survival in patients with acuteon-chronic liver failure. Indian J Gastroenterol 2016;35(06): 432-440

44 Joshi N, Kopec AK, Ray JL, et al. Von Willebrand factor deficiency reduces liver fibrosis in mice. Toxicol Appl Pharmacol 2017; 328:54-59

45 Geys L, Bauters D, Roose E, et al. ADAMTS13 deficiency promotes microthrombosis in a murine model of diet-induced liver steatosis. Thromb Haemost 2017;117(01):19-26

46 Lancellotti S, Basso M, Veca V, et al. Presence of portal vein thrombosis in liver cirrhosis is strongly associated with low levels of ADAMTS-13: a pilot study. Intern Emerg Med 2016;11 (07):959-967

47 Villa E, Cammà C, Marietta M, et al. Enoxaparin prevents portal vein thrombosis and liver decompensation in patients with advanced cirrhosis. Gastroenterology 2012;143(05):1253$-1260 . e 4$

48 De Caterina R, Husted S, Wallentin L, et al; General mechanisms of coagulation and targets of anticoagulants (Section I). Position Paper of the ESC Working Group on Thrombosis-Task Force on Anticoagulants in Heart Disease. Thromb Haemost 2013;109 (04):569-579

49 Barnes GD, Ageno W, Ansell J, Kaatz S; Subcommittee on the Control of Anticoagulation of the International Society on Thrombosis and Haemostasis. Recommendation on the nomenclature for oral anticoagulants: communication from the SSC of the ISTH. J Thromb Haemost 2015;13(06):1154-1156 
50 Cohen AT, Spiro TE, Büller HR, et al; MAGELLAN Investigators. Rivaroxaban for thromboprophylaxis in acutely ill medical patients. N Engl J Med 2013;368(06):513-523

51 Bauersachs R, Berkowitz SD, Brenner B, et al; EINSTEIN Investigators. Oral rivaroxaban for symptomatic venous thromboembolism. N Engl J Med 2010;363(26):2499-2510

52 Agnelli G, Buller HR, Cohen A, et al; AMPLIFY-EXT Investigators. Apixaban for extended treatment of venous thromboembolism. N Engl J Med 2013;368(08):699-708

53 Eriksson BI, Dahl OE, Rosencher N, et al; RE-MODEL Study Group. Oral dabigatran etexilate vs. subcutaneous enoxaparin for the prevention of venous thromboembolism after total knee replacement: the RE-MODEL randomized trial. J Thromb Haemost 2007;5(11):2178-2185

54 Schulman S, Kearon C, Kakkar AK, et al; RE-MEDY Trial Investigators; RE-SONATE Trial Investigators. Extended use of dabigatran, warfarin, or placebo in venous thromboembolism. N Engl J Med 2013;368(08):709-718

55 Connolly SJ, Ezekowitz MD, Yusuf S, et al; RE-LY Steering Committee and Investigators. Dabigatran versus warfarin in patients with atrial fibrillation. N Engl J Med 2009;361(12): 1139-1151

56 Giugliano RP, Ruff CT, Braunwald E, et al; ENGAGE AF-TIMI 48 Investigators. Edoxaban versus warfarin in patients with atrial fibrillation. N Engl J Med 2013;369(22):2093-2104

57 Büller HR, Décousus H, Grosso MA, et al; Hokusai-VTE Investigators. Edoxaban versus warfarin for the treatment of symptomatic venous thromboembolism. N Engl J Med 2013;369(15): 1406-1415

58 Cohen AT, Harrington RA, Goldhaber SZ, et al; APEX Investigators. Extended thromboprophylaxis with betrixaban in acutely ill medical patients. N Engl J Med 2016;375(06):534-544

59 Weitz JI, Lensing AWA, Prins MH, et al; EINSTEIN CHOICE Investigators. Rivaroxaban or aspirin for extended treatment of venous thromboembolism. N Engl J Med 2017;376(13): 1211-1222

60 Patel MR, Mahaffey KW, Garg J, et al; ROCKET AF Investigators. Rivaroxaban versus warfarin in nonvalvular atrial fibrillation. $\mathrm{N}$ Engl J Med 2011;365(10):883-891

61 Büller HR, Prins MH, Lensin AW, et al; EINSTEIN-PE Investigators. Oral rivaroxaban for the treatment of symptomatic pulmonary embolism. N Engl J Med 2012;366(14):1287-1297

62 Lassen MR, Raskob GE, Gallus A, Pineo G, Chen D, Portman RJ. Apixaban or enoxaparin for thromboprophylaxis after knee replacement. N Engl J Med 2009;361(06):594-604

63 Lassen MR, Gallus A, Raskob GE, Pineo G, Chen D, Ramirez LM; ADVANCE-3 Investigators. Apixaban versus enoxaparin for thromboprophylaxis after hip replacement. N Engl J Med 2010;363(26):2487-2498

64 Goldhaber SZ, Leizorovicz A, Kakkar AK, et al; ADOPT Trial Investigators. Apixaban versus enoxaparin for thromboprophylaxis in medically ill patients. N Engl J Med 2011;365(23): 2167-2177

65 Connolly SJ, Eikelboom J, Joyner C, et al; AVERROES Steering Committee and Investigators. Apixaban in patients with atrial fibrillation. N Engl J Med 2011;364(09):806-817

66 Bruins Slot KM, Berge E. Factor Xa inhibitors versus vitamin K antagonists for preventing cerebral or systemic embolism in patients with atrial fibrillation. Cochrane Database Syst Rev 2018;3:CD008980

67 Robertson L, Kesteven P, McCaslin JE. Oral direct thrombin inhibitors or oral factor Xa inhibitors for the treatment of deep vein thrombosis. Cochrane Database Syst Rev 2015;(06): CD010956

68 Kubitza D, Roth A, Becka M, et al. Effect of hepatic impairment on the pharmacokinetics and pharmacodynamics of a single dose of rivaroxaban, an oral, direct Factor Xa inhibitor. Br J Clin Pharmacol 2013;76(01):89-98
69 Graff J, Harder S. Anticoagulant therapy with the oral direct factor Xa inhibitors rivaroxaban, apixaban and edoxaban and the thrombin inhibitor dabigatran etexilate in patients with hepatic impairment. Clin Pharmacokinet 2013;52(04):243-254

70 Camm AJ, Bounameaux H. Edoxaban: a new oral direct factor Xa inhibitor. Drugs 2011;71(12):1503-1526

71 Mendell J, Johnson L, Ridout G, He L, Chen S. An open-label phase 1 study to evaluate the effects of hepatic impairment on edoxaban pharmacokinetics. Eur Heart J 2012;33(S1):Abstract 2024

72 Chan NC, Bhagirath V, Eikelboom JW. Profile of betrixaban and its potential in the prevention and treatment of venous thromboembolism. Vasc Health Risk Manag 2015;11:343-351

73 Clinicaltrials NIH. gov. The Effect of Hepatic Impairment on the Pharmacokinetics and Pharmacodynamics of Betrixaban, an Oral FXa Antagonist. Available at: https://clinicaltrials.gov/ct2/show/ NCT03397888. Accessed September 24, 2018

74 De Gottardi A, Seijo S, Plessier A, et al. 0077: use of direct oral anticoagulants (DOACs) in patients with splanchnic vein thrombosis and/or cirrhosis. J Hepatol 2015;62:S229

75 De Gottardi A, Trebicka J, Klinger C, et al; VALDIG Investigators. Antithrombotic treatment with direct-acting oral anticoagulants in patients with splanchnic vein thrombosis and cirrhosis. Liver Int 2017;37(05):694-699

76 Hum J, Shatzel JJ, Jou JH, Deloughery TG. The efficacy and safety of direct oral anticoagulants vs traditional anticoagulants in cirrhosis. Eur J Haematol 2017;98(04):393-397

77 Intagliata NM, Henry ZH, Maitland H, et al. Direct oral anticoagulants in cirrhosis patients pose similar risks of bleeding when compared to traditional anticoagulation. Dig Dis Sci 2016; 61(06):1721-1727

78 Nagaoki Y, Aikata H, Daijyo K, et al. Efficacy and safety of edoxaban for treatment of portal vein thrombosis following danaparoid sodium in patients with liver cirrhosis. Hepatol Res 2018;48(01):51-58

79 Hanafy AS, Abd-Elsalam S, Dawoud MM. Randomized controlled trial of rivaroxaban versus warfarin in the management of acute non-neoplastic portal vein thrombosis. Vascul Pharmacol 2018: S1537-1891(18)30099-5

80 Scheiner B, Stammet PR, Pokorny S, et al. Anticoagulation in nonmalignant portal vein thrombosis is safe and improves hepatic function. Wien Klin Wochenschr 2018. Doi: 10.1007/s00508018-1351-y

81 Pastori D, Lip GYH, Farcomeni A, et al; ATHERO-AF study group. Incidence of bleeding in patients with atrial fibrillation and advanced liver fibrosis on treatment with vitamin $\mathrm{K}$ or nonvitamin $\mathrm{K}$ antagonist oral anticoagulants. Int J Cardiol 2018; 264:58-63

82 Janczak DT, Mimier MK, McBane RD, et al. Rivaroxaban and apixaban for initial treatment of acute venous thromboembolism of atypical location. Mayo Clin Proc 2018;93(01):40-47

83 Intagliata NM, Maitland H, Northup PG, Caldwell SH. Treating thrombosis in cirrhosis patients with new oral agents: ready or not? Hepatology 2015;61(02):738-739

84 Lenz K, Dieplinger B, Buder R, Piringer P, Rauch M, Voglmayr M. Successful treatment of partial portal vein thrombosis (PVT) with low dose rivaroxaban. Z Gastroenterol 2014;52(10): 1175-1177

85 Martinez M, Tandra A, Vuppalanchi R. Treatment of acute portal vein thrombosis by nontraditional anticoagulation. Hepatology 2014;60(01):425-426

86 Qi X, Yoshida EM, Mendez-Sanchez N, Guo X. Rivaroxaban recanalized occlusive superior mesenteric vein thrombosis, but increased the risk of bleeding in a cirrhotic patient. Liver Int 2017;37(10):1574-1575

87 Yang H, Kim SR, Song MJ. Recurrent acute portal vein thrombosis in liver cirrhosis treated by rivaroxaban. Clin Mol Hepatol 2016; 22(04):499-502 
88 Pannach S, Babatz J, Beyer-Westendorf J. Successful treatment of acute portal vein thrombosis with rivaroxaban. Thromb Haemost 2013;110(04):626-627

89 NIH ClinicalTrials.gov. Multicenter Prospective Randomized Trial of the Effect of Rivaroxaban on Survival and Development of Complications of Portal Hypertension in Patients with Cirrhosis. Available at: https://clinicaltrials.gov/ct2/show/NCT02643212. Accessed September 24, 2018

90 NIH ClinicalTrials.gov. Xarelto Versus no Treatment for the Prevention of Recurrent Thrombosis in Patients With Chronic Portal Vein Thrombosis. Available at: https://clinicaltrials.gov/ct2/ show/NCT02555111. Accessed September 24, 2018

91 Ponziani FR, De Candia E, De Cristofaro R, Pompili M. Portal vein thrombosis occurrence in a cirrhotic patient during treatment with rivaroxaban. Liver Int 2017;37(08):1251

92 Cutts BA, Dasgupta D, Hunt BJ. New directions in the diagnosis and treatment of pulmonary embolism in pregnancy. Am J Obstet Gynecol 2013;208(02):102-108

93 Bapat P, Kedar R, Lubetsky A, et al. Transfer of dabigatran and dabigatran etexilate mesylate across the dually perfused human placenta. Obstet Gynecol 2014;123(06):1256-1261

94 Bapat P, Pinto LSR, Lubetsky A, Berger H, Koren G. Rivaroxaban transfer across the dually perfused isolated human placental cotyledon. Am J Obstet Gynecol 2015;213(05):710.e1-710.e6

95 Bapat P, Pinto LSRR, Lubetsky A, et al. Examining the transplacental passage of apixaban using the dually perfused human placenta. J Thromb Haemost 2016;14(07):1436-1441

96 Hoeltzenbein M, Beck E, Meixner K, Schaefer C, Kreutz R. Pregnancy outcome after exposure to the novel oral anticoagulant rivaroxaban in women at suspected risk for thromboembolic events: a case series from the German Embryotox Pharmacovigilance Centre. Clin Res Cardiol 2016;105(02): $117-126$

97 Beyer-Westendorf J, Michalski F, Tittl L, et al. Pregnancy outcome in patients exposed to direct oral anticoagulants - and the challenge of event reporting. Thromb Haemost 2016;116(04): 651-658

98 Wang L, He K, Maxwell B, et al. Tissue distribution and elimination of [14C]apixaban in rats. Drug Metab Dispos 2011;39(02): 256-264

99 Wiesen MHJ, Blaich C, Müller C, Streichert T, Pfister R, Michels G. The direct factor Xa inhibitor rivaroxaban passes into human breast milk. Chest 2016;150(01):e1-e4

100 Ruff CT, Giugliano RP, Braunwald E, et al. Comparison of the efficacy and safety of new oral anticoagulants with warfarin in patients with atrial fibrillation: a meta-analysis of randomised trials. Lancet 2014;383(9921):955-962

101 Coleman CI, Peacock WF, Bunz TJ, Alberts MJ. Effectiveness and safety of apixaban, dabigatran, and rivaroxaban versus warfarin in patients with nonvalvular atrial fibrillation and previous stroke or transient ischemic attack. Stroke 2017;48(08): 2142-2149

102 Lip GYH, Pan X, Kamble S, et al. Major bleeding risk among nonvalvular atrial fibrillation patients initiated on apixaban, dabigatran, rivaroxaban or warfarin: a "real-world" observational study in the United States. Int J Clin Pract 2016;70(09):752-763

103 Jacobs V, May HT, Bair TL, et al. Long-term population-based cerebral ischemic event and cognitive outcomes of direct oral anticoagulants compared with warfarin among long-term anticoagulated patients for atrial fibrillation. Am J Cardiol 2016;118 (02):210-214

104 Abraham NS, Singh S, Alexander GC, et al. Comparative risk of gastrointestinal bleeding with dabigatran, rivaroxaban, and warfarin: population based cohort study. BMJ 2015;350(02): h1857-h1857

105 Chang H-Y, Zhou M, Tang W, Alexander GC, Singh S. Risk of gastrointestinal bleeding associated with oral anticoagulants: population based retrospective cohort study. BMJ 2015;350(01): h1585-h1585

106 Cangemi DJ, Krill T, Weideman R, Cipher DJ, Spechler SJ, Feagins LA. A comparison of the rate of gastrointestinal bleeding in patients taking non-vitamin $\mathrm{K}$ antagonist oral anticoagulants or warfarin. Am J Gastroenterol 2017;112(05):734-739

107 Nagata N, Yasunaga H, Matsui H, et al. Therapeutic endoscopyrelated GI bleeding and thromboembolic events in patients using warfarin or direct oral anticoagulants: results from a large nationwide database analysis. Gut 2018;67(10):1805-1812

108 Reilly PA, Lehr T, Haertter S, et al; RE-LY Investigators. The effect of dabigatran plasma concentrations and patient characteristics on the frequency of ischemic stroke and major bleeding in atrial fibrillation patients: the RE-LY Trial (Randomized Evaluation of Long-Term Anticoagulation Therapy). J Am Coll Cardiol 2014;63 (04):321-328

109 Caldeira D, Barra M, Santos AT, et al. Risk of drug-induced liver injury with the new oral anticoagulants: systematic review and meta-analysis. Heart 2014;100(07):550-556

110 Raschi E, Poluzzi E, Koci A, et al. Liver injury with novel oral anticoagulants: assessing post-marketing reports in the US Food and Drug Administration adverse event reporting system. Br J Clin Pharmacol 2015;80(02):285-293

111 Bunchorntavakul C, Reddy KR. Drug hepatotoxicity: newer agents. Clin Liver Dis 2017;21(01):115-134

112 Anastasia EJ, Rosenstein RS, Bergsman JA, Parra D. Use of apixaban after development of suspected rivaroxaban-induced hepatic steatosis; a case report. Blood Coagul Fibrinolysis 2015; 26(06):699-702

113 Tomaselli GF, Mahaffey KW, Cuker A, et al. 2017 ACC Expert Consensus Decision Pathway on Management of Bleeding in Patients on Oral Anticoagulants: a report of the American College of Cardiology Task Force on Expert Consensus Decision Pathways. J Am Coll Cardiol 2017;70(24):3042-3067

114 Pollack CV Jr, Reilly PA, Eikelboom J, et al. Idarucizumab for dabigatran reversal. N Engl J Med 2015;373(06):511-520

115 Pollack CV Jr, Reilly PA, van Ryn J, et al. Idarucizumab for dabigatran reversal - full cohort analysis. N Engl J Med 2017; 377(05):431-441

116 Connolly SJ, Milling TJ Jr, Eikelboom JW, et al; ANNEXA-4 Investigators. Andexanet alfa for acute major bleeding associated with factor Xa inhibitors. N Engl J Med 2016;375(12):1131-1141

117 De Gottardi A, Garcia-Pagan JC; VALDIG Investigators. The anticoagulant efficacy of rivaroxaban may be attenuated in cirrhotic patients. Liver Int 2017;37(08):1252

118 Potze W, Arshad F, Adelmeijer J, et al. Differential in vitro inhibition of thrombin generation by anticoagulant drugs in plasma from patients with cirrhosis. PLoS One 2014;9(02): e88390 